\title{
Effects of Service Quality, Social Environment and Financial on Motivation, Satisfaction, and Performance for Athletes at Training Center PON XX in DIY
}

\author{
Agung Nugroho, Tomoliyus", Sumaryanto, Ilham \\ Faculty of Sport Sciences, Yogyakarta State University, Indonesia
}

Received July 13, 2021; Revised September 2, 2021; Accepted September 21, 2021

\section{Cite This Paper in the following Citation Styles}

(a): [1] Agung Nugroho, Tomoliyus, Sumaryanto, Ilham , "Effects of Service Quality, Social Environment and Financial on Motivation, Satisfaction, and Performance for Athletes at Training Center PON XX in DIY," International Journal of Human Movement and Sports Sciences, Vol. 9, No. 5, pp. 1067 - 1079, 2021. DOI: 10.13189/saj.2021.090529.

(b): Agung Nugroho, Tomoliyus, Sumaryanto, Ilham (2021). Effects of Service Quality, Social Environment and Financial on Motivation, Satisfaction, and Performance for Athletes at Training Center PON XX in DIY. International Journal of Human Movement and Sports Sciences, 9(5), 1067 - 1079. DOI: 10.13189/saj.2021.090529.

Copyright $@ 2021$ by authors, all rights reserved. Authors agree that this article remains permanently open access under the terms of the Creative Commons Attribution License 4.0 International License

\begin{abstract}
Background: The training center programs are integrated exercises carried out by the Indonesian National Sports Committee (INSC) in the Yogyakarta region in preparing for the weekly National Sports (PON $\mathrm{XX)}$ multi-event in Papua. Purpose: The aim was to explore a deeper understanding along examining empirically variable-indicators relationships, simply known as the correlation of service quality, financial support, social environment, motivation, satisfaction, and athlete performance in sports. Design/method/approach: The research is descriptive with the mixed method. The approach was tested using structural equation modeling involving 137 athletes from the training center-INSC in Yogyakarta. Results: The scale/indicators and items used to evaluate the relationship of the variables and whether variable-indicators are valid and meaningful. By employing SPSS.23 and Smart PLS-SEM while testing data, construct validity and reliability compounds (Cronbach's alpha, rho-A, composite reliability, and AVE) were all verified and valid. When testing the correlation between indicators-variables, significance correlation was found in almost relation. However, correlating between variables-variables, a large number of data did not verify such correlation. The expected reason was that the researcher employed many variables with multiples items in one study. Linear regression was also analyzed and found in some aspects with P-value $<0.05$. Conclusion: Although not all results showed a significant effect
\end{abstract}

especially on dependent variables, service quality, social environment, financial support should be elaborated in the wake of improving satisfaction, motivation, and athlete achievement. As a suggestion, it could be the first study to be applied directly to the current situation in the PON $\mathrm{XX}$-DIY training center programs.

Keywords Service Quality, Social Environment, Financial, Motivation, Satisfaction, Athlete Performance

\section{Introduction}

The weekly National Sports shortened PON XX in the Javanese language is the highest and most prestigious and famous multi-event sporting performed in Indonesia. To take part in this national and cultural event especially in the Special Region of Yogyakarta (DIY), athletes must get prepared for regional training centers as a mandatory requirement, (Training Center Region). However, to our better knowledge, the success of any competitive activity is the requirement of a combination of throughput on both sides (trainers and trainees). Rigorous preparation and robust determination of subjects are also indispensable assets [1]. In sports, for instance, good management is strongly attributed to success especially in the wake of achieving comfort in sports as one of the largest social 
events in the world that yield countless benefits [2], [3]. In tandem, increasing sports achievement is generally associated with the provision of good sports facilities as well. For [4], the provision of sports facilities is one of the prominent factors that contribute to community participation in sports activities. Likewise, parental involvements in children's sports careers are also very important in offering equipment support, spectators, to manage emotional and psychological feelings from practical perspectives. The family environment has probably been the most accessible and most important socio-environmental dimension of the success of young athletes so far [5].

The Training Center or TC, in short, involves athletes, coaches, and the Indonesian National Sports Committee otherwise Komite Olahraga Nasional Indonesia/KONI in the Javanese language) dealing with services that require hospitality and athletes' coaching. Transforming empathy into compassion for passionate athletes can be viewed as an emotion-regulating strategy that buffers negative influences of positive influences that rely on brain circuits related to values and affiliation [6]. It is worth mentioning that the involvement of athletes in training center consisting of all both gender (male and female) athletes in the preparation of multi-events which has an influence on the athlete's social environment. Hence, in a broad sense, sport can be a useful instrument that supports social engagement for boys and girls professional or novice athletes. Besides, the implementation of training center KONI DIY for concerns should also be supported by the need for funds to purchase exercise equipment, try out/try in support, pocket money, extra and nutritional foods, transportation, psychological and physiotherapy services, and other staple needs relating to the well-being of the athletes.

However, since the covid-19 pandemic is recognized as an unprecedented disease, there has been a disturbance, drastic changes, and needs never than before attributed to the same disease. For that reason, knowledge gaps to keep on coaching athletes were indeed disrupted, and short-term individual changes in psychological conditions were readily manifested. Thus, based on the benefits and the role-playing by training center in nurturing education and character of young generation in general, it can be considered as a reference for policymakers to reform, amend and effectively increase stability, popular feeling and immediately sustain and underpin clinical practitioners to provide a suitable and basic therapeutic for these valuable individuals [7]. The needs latter audited could support the continuity of training center PON DIY and ease the implementation of their programs. Interestingly, this claim and appeal made here are not heard at the same level. That said there is a time when some wish to have what others have. We acknowledge that training center KONI in DIY needs support. However, when compared to several other regions DIY's KONI funding reserved in the preparation of 2021 is among the best. For the PON in Papua for instance, the budget for that is still relatively small and derisory, even though the achievement target that DIY expects is quite different, namely 2021 eleven (11) gold medals. Financial assistance provided by KONI-DIY in the form of pocket money to athletes and coaches is given every month as extrinsic motivation.

In the training center, motivational encouragement from athletes is needed and is of paramount importance [8], however, it is negatively affected by incentive-related expectation gaps, including (1) lower than expected financial incentives, (2) slower payouts than expected, (3) material paucity and job-enabling incentives than expected, and (4) incentives that are unequally distributed across athletes [9]. The timeliness of granting funds to athletes PON in DIY training centers can affect the motivation of athletes in habitual training sessions. For this reason, providing funding for high-performing athletes allows exclusive dedication to training and subsequently better achievements in national and international competitions [10]. For trainers, job satisfaction and intrinsic motivation moderate the relationship between work ethics and organizational commitment, and work performance. This is a big issue and challenge as well as an opportunity for training center PON XX in Papua to claim the rights and to increase the value of their athletes along with their skills. These facts outlined here could be an educative and directive hint to lead them to the accomplishment of their dreams. To our better knowledge, as far as no one was interested to find out the extent to which is the relationship of service quality, social environment, finance, satisfaction, on athletes' motivation and performance in the implementation of training center programs PON XX in Papua. Thus, the present study intends to reveal these relations and then describe the importance of service quality, social environment, and financial support on motivation, satisfaction, and performance of athletes.

The execution of this research is very important and needed so far due to its predictable contribution that may bring to KONI DIY in the preparation of training center programs in multi-sport events and for other athletic training centers. To this end, it can improve the quality management of service quality, social environment, finance, which can affect the motivation, satisfaction, and performance of athletes at different levels.

\section{Material and Research Methodology}

\subsection{Research Design}

The nature of this research on hands is a descriptive study with mixed design quantitative and qualitative approaches. In broad terms, the mixed methods research is the type of research in which a researcher (s) combines elements of qualitative and quantitative research 
approaches for the broad purposes of breadth and depth of understanding and corroboration [11]. While conducting any research, it is possible to answer the research questions by employing a qualitative and quantitative method. The study is descriptive-correlational research that seeks to reveal the extent to which is the correlation or effect of the research variables, namely service quality, social environment, and financial on motivation, satisfaction, and performance for young athletes in the Yogyakarta region. To operationalize the constructs in our research model on the outset, validated scales were adapted and modified. All items were measured using a four-point Likert type scale, ranging from 1 (strongly disagree) to 4 (strongly agree) as a negative perception, and from 4 (strongly agree) up to 1 (strongly disagree) as a positive perception. All items used in this research were firstly endorsed by experts in the academic sector, and minor revisions were suggested and made to the questionnaire.

\subsection{Variable and Measurements Procedures}

This survey with qualitative and quantitative approaches was conducted at the training center of the Indonesian National Sports Committee in Yogyakarta in preparation for the weekly XX National Sports multi-event hosted in Papua in 2021. Data collection methods are techniques through which the researcher would carefully select for his/her own study based on nature, scope and objects of inquiry [12], and find availability and time factor [13]. Through these measurements, primary data and secondary data were used in the wake of responding to the current research objectives. During primary data harvesting, this study adopted structured-undisguised type of questionnaire because revealing the study purpose was anticipated to minimize the difficult. On the other hands, primary data were supported by the secondary data in the follow-up steps to strengthen the gist content of the primary data. Constructing suitable literature review deemed useful in our study, such as related findings, were collected from past researches executed on the athlete's performance in general.

\subsection{Questionnaire Designs and Measures}

The six main variables along with eighteen indicators guide the study to bridge and cover the research gap and objectives, the minimum of 3 items for each indicator were built. Then, the survey contained 52 items encompassed in 18 indicators of which most of them were adopted from the Service Quality Assessment Scale [14], [15]. [16], and so forth. However, only 39 items were selected and used during data analysis due to their loading values validity based on the Cronbach alpha results. The rest fourteen items were excluded during data processing.

\subsection{Sampling and Data Collection}

We measure the causal/effect of relationships between the research variables in the training center In the Yogyakarta region. The population consists of the training center of the Indonesian National Sports Committee in Yogyakarta in preparation for the weekly XX National Sports multi-event hosted in Papua in 2021. The number of training center athletes who partook in this study is 137 athletes as sample size, dividing into 24 sub-sports. The subjects voluntarily selected were able to provide all the necessary information and answer the research questions. Data collection employs a set questionnaire along with online structured interview via Google form platform to reach information while it was hard to meet the subject due to the ongoing pandemic. However, a kind of interview was conducted to get more qualitative information.

\subsection{Model Selection and Development}

The model employed was selected and developed based on theoretical framework designed that their main content overlapped and intertwined one another. By defining the vital role service quality in spots stand for in generating athletes motivation, social environment was also deemed to become another useful indicator which contributes in athlete performance and achievement [17]. As far as financial support is concerned, the emphasis was put on that finance status is not the main need for athletes, but adequate finances could encourage the athletes performance and satisfactory achievement [18]. At the same time, athletes' satisfaction can be realized if the athlete's expectations are met according to their needs [19]. Nevertheless, if the results obtained exceed the desired expectations, the athlete's satisfaction will be fulfilled. Thus, to achieve athletes' satisfaction, it is necessary to pay attention to the service quality of factors, namely tangible, empathy, reliability, responsiveness, and assurance along with other intermediate or extraneous factor in athletes' performance. Based on the framework audited above, the researcher describes the research paradigm of the relationship between the variables of service quality, social environment, finance, motivation, satisfaction, and athlete performance as shown in the following research paradigm alias the structure of the correlational modelling research. 


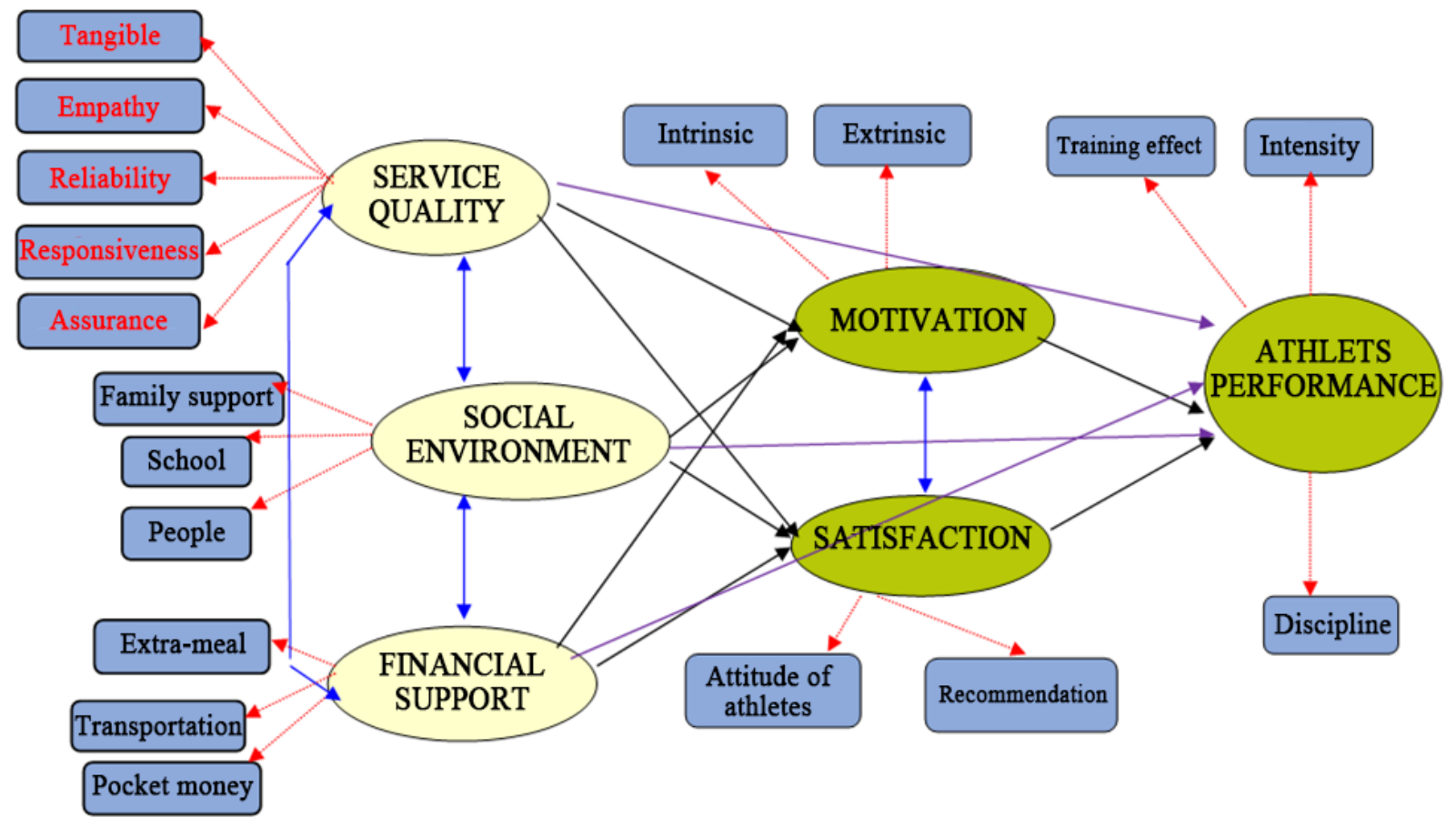

Diagram 1. Structure of the Correlational Modelling Research

\subsection{Data Analysis}

We employed Smart-PLS [20] to estimate research model parameters and the correlation between indicators and variables. This research has three independent variables and three dependent variables to look for their causal relationships. This study compiles many variables and indicators at once that have been summarized in the following Structural Equation Model Research designed by the research in the wake of easing and presenting all research constructs and webbed liaisons.

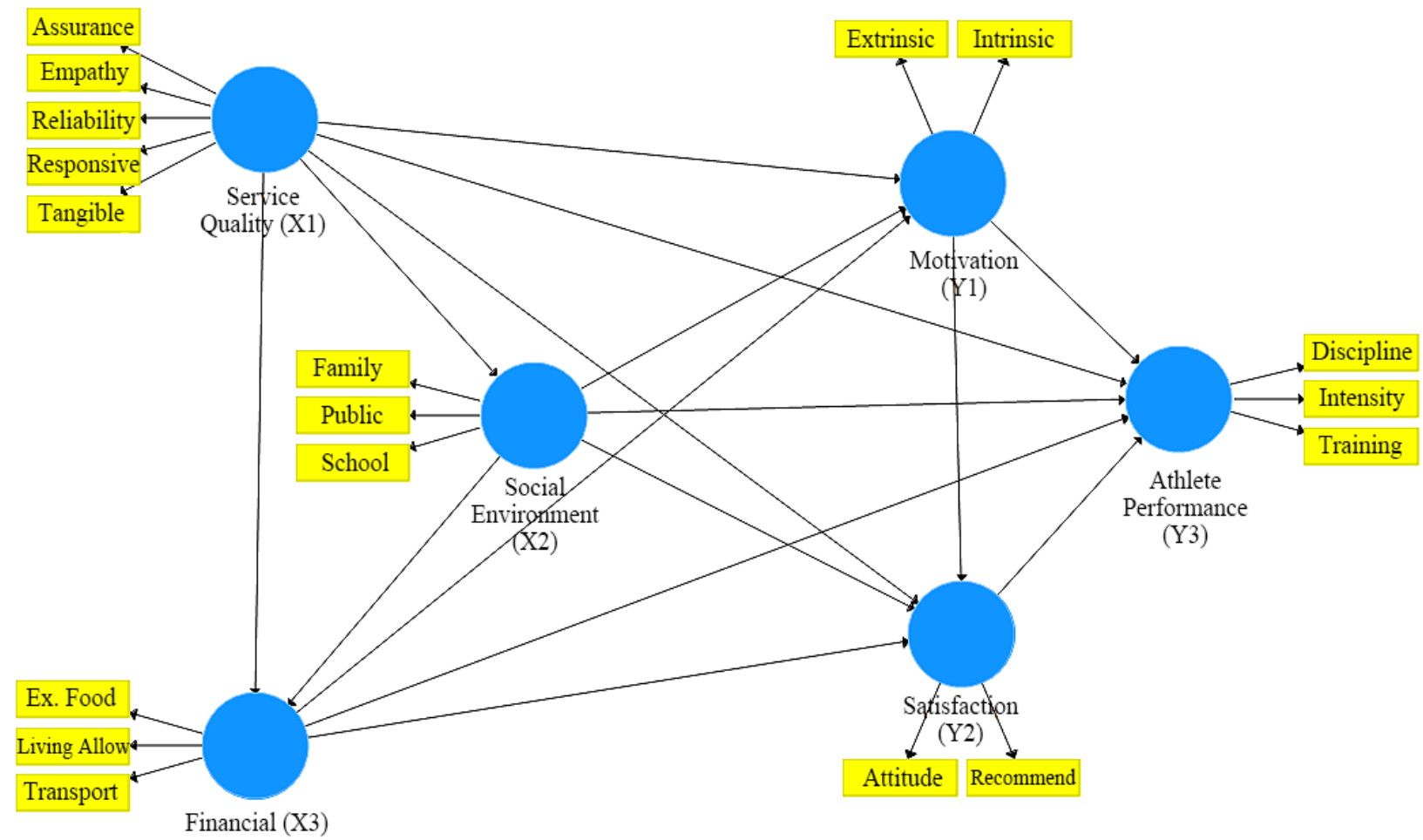

Diagram 2. The proposed Network-Model of Research Variable-Indicators 
The above-depicted diagram shows the identity of independent variables, namely service quality, social environment, and financial support, whereas dependent variables consist of motivation, satisfaction, and athlete's performance. It is worth mentioning that previous studies have reported differing levels of these relations regarding the impact or effect of service quality on motivation or athlete performance [21], [22], the impact of social environment on motivation, and athlete performance [23]. Besides, financial support was also found to have made a significant contribution to motivation and athlete performance [24], [16], and so forth. In the same vein, other studies having investigated the extent to which is the correlation between research variables and their indicators. For instance, [25]sought the relation between service quality and responsiveness where their findings revealed such evidence without forgetting training intensity and athlete's performance [26]. Therefore, the following hypotheses are set up as follows:

H1: There is a significant correlation between research indicators and variables.

H2: There is a positive correlation between dependent and independent variables.

H3: There is a linear regression between dependent variables and independents ones.
The Research Structural Equation Modeling in Smart-PLS Software

To begin with, the following diagram 3 below will help us to find out the correlation that will exist between the indicators and the variables. The next concern is the correlation that will exist between the variables themselves as the research hypotheses demonstrated above.

This research structural equation modeling has six main variables and eighteen indicators distributed as follows; four indicators (tangible, empathy, reliability, responsiveness, and assurance) for the service quality variable; 3 indicators (family support, school, and people); the social environment variable is an independent variable; three others for financial support variable encompasses extra-meal, transportation fee, and pocket money. On the other side, the dependent variable namely motivation has two indicators, which is intrinsic and extrinsic factors, satisfaction variable was assigned two indicators namely attitude of athletes and recommendation. However, athlete's performance that is the last dependent variable was connected to three indicators, namely training effect, intensity, and discipline. This information presented above can be viewed in Diagram 3 below: 


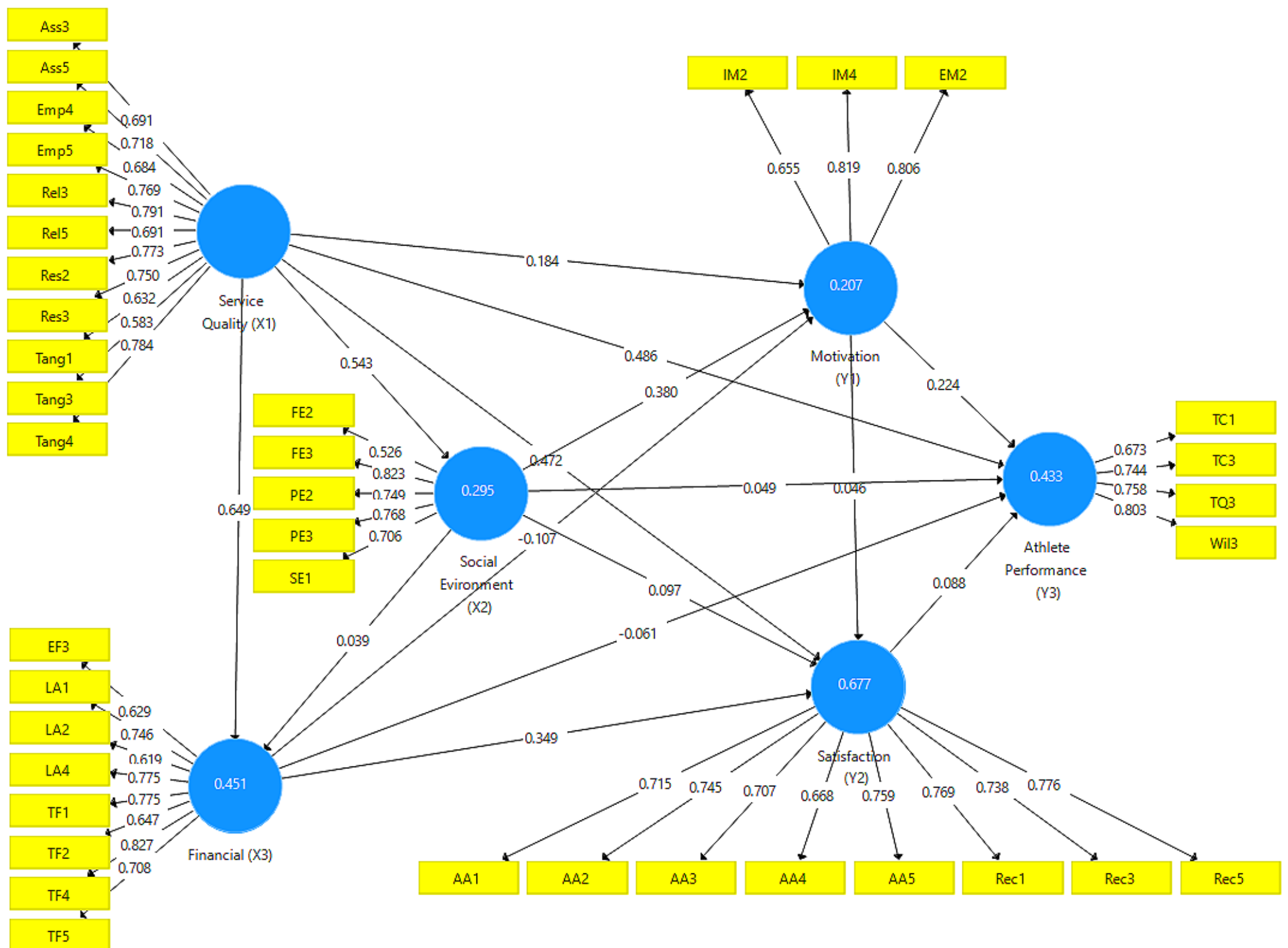

Diagram 3. The relationship or correlation between indicators and variables 
The diagram above describes the relationship or correlation between indicators and variables and whether there is any influence from the indicator on the variable or the influence between variables themselves. The outcome of the research focused on the types of correlation like a strong positive correlation from 1 to $(0.5)$ and a strong negative correlation from -1 to $(-0.5)$ while the weak correlation is positive between 0.5 and 0.00 while a weak negative correlation from -0.5 to 0.00 . After addressing all data, findings proved the strong correlation between almost all indicators that ranged from 0.828 to 0.529 .

\subsection{Data Analysis Process}

In this study, we used the PLS-SEM method and the statistical software Smart-PLS to estimate the model. There are relationships that reside between research variables and indicators [27]. PLS-SEM is a multivariate analysis approach used to estimated path models with latent variables. With previous studies having identified a sampling threshold for PLS-SEM in the order of 100 samples, the current sample sizes of 137 subjects would generally be seen as adequate for this tool [28].

\section{Analysis and Results}

The assessment of the reflective measurement model entails an evaluation of its reliability and validity of items with respect to the latent variables [29], [30]. This involves assessing the relationships between the latent variables and their associated items through indicators. For [31], [32], validity is explained as the degree or the extent to which a test measures what is presumed to measure. Internal consistency reliability and convergence validity are often assessed by way of two key coefficients: composite reliability (CR) and average variance extracted (AVE). As mentioned in the preceding section, the measurement models used in this study included six main constructs along with eighteen indicators. According to [27], in assessing reliability of a model, the loading of each indicator on its associated latent variables must be calculated and compared to a threshold. For [33], the output loadings should be higher than 0.7 for indicators reliability/composite reliability to be considered acceptable. In our research, all-composite reliability values were cohesive with such assumption and loaded above the 0.70 as the recommended value. The lowest value was 0.806 whereas the highest one values 0.921 . According to [34], if the AVE value is greater than 0.5 , the indicator/items measuring the variable can be said to be valid and reliable. On the side of Cronbach's alpha values, loading values were also above 0.6 . The rho_A is also used for assessing construct reliability, which should be higher than 0.7 to establish internal consistency. Based on the results we have, it is obviously seen that all research variables loading values were higher than 0.70 except motivation variable where its value was equal to 0,641 . Thus, these results indicate that the measurement model and calculations possessed acceptable reliability.

To assess collinearity statistically, our concern was put on the variance inflation factor henceforth VIF. As can be viewed from the table below, the conclusion of VIF in our study is well below the threshold value of 5 , which said that collinearity is not a problem [35].

Table 1. Output for Construct and Reliability and Validity

\begin{tabular}{|c|c|c|c|c|}
\hline & Cronbach's Alpha & rho_A & $\begin{array}{c}\text { Composite } \\
\text { Reliability }\end{array}$ & $\begin{array}{c}\text { Average Variance } \\
\text { Extracted (AVE) }\end{array}$ \\
\hline Athlete Performance (Y3) & 0.733 & 0.736 & 0.833 & 0.557 \\
\hline Financial (X3) & 0.865 & 0.865 & 0.895 & 0.517 \\
\hline Motivation (Y1) & 0.636 & 0.641 & 0.806 & 0.583 \\
\hline Satisfaction (Y2) & 0.879 & 0.882 & 0.904 & 0.541 \\
\hline Service Quality (X1) & 0.905 & 0.908 & 0.921 & 0.516 \\
\hline Social Evironment (X2) & 0.761 & 0.764 & 0.842 & 0.521 \\
\hline
\end{tabular}


Table 2. The Outputs of Collinearity Assessment (VIF)

\begin{tabular}{|c|c|c|c|c|c|c|c|c|c|c|c|}
\hline No & Collin. & Value & No & Collin. & Value & No & Collin. & Value & No & Collin. & Value \\
\hline 1 & AA1 & 2.466 & 11 & Emp5 & 2.649 & 21 & Rec1 & 2.099 & 31 & TF1 & 2.272 \\
\hline 2 & AA2 & 2.531 & 12 & FE2 & 1.153 & 22 & Rec3 & 1.975 & 32 & TF2 & 1.67 \\
\hline 3 & AA3 & 1.726 & 13 & FE3 & 2.422 & 23 & Rec5 & 2.399 & 33 & TF4 & 2.929 \\
\hline 4 & AA4 & 1.78 & 14 & IM2 & 1.096 & 24 & Rel3 & 2.675 & 34 & TF5 & 1.609 \\
\hline 5 & AA5 & 1.903 & 15 & IM4 & 1.527 & 25 & Rel5 & 1.954 & 35 & TQ3 & 1.383 \\
\hline 6 & Ass3 & 2.109 & 16 & LA1 & 1.893 & 26 & Res2 & 2.713 & 36 & Tang1 & 1.731 \\
\hline 7 & Ass5 & 2.17 & 17 & LA2 & 1.394 & 27 & Res3 & 2.56 & 37 & Tang3 & 1.596 \\
\hline 8 & EF3 & 1.4 & 18 & LA4 & 2.506 & 28 & SE1 & 1.457 & 38 & Tang4 & 2.58 \\
\hline 9 & EM2 & 1.562 & 19 & PE2 & 1.722 & 29 & TC1 & 1.234 & 39 & Wil3 & 1.678 \\
\hline 10 & Emp4 & 2.121 & 20 & PE3 & 2.229 & 30 & TC3 & 1.535 & 40 & & \\
\hline
\end{tabular}

Table 3. Discriminant Validity among Variables

\begin{tabular}{|c|c|c|c|c|c|c|}
\hline & $\begin{array}{c}\text { Athlete } \\
\text { Perfor. (Y3) }\end{array}$ & $\begin{array}{c}\text { Financial } \\
\text { (X3) }\end{array}$ & $\begin{array}{c}\text { Motivation } \\
\text { (Y1) }\end{array}$ & $\begin{array}{c}\text { Satisfaction } \\
\text { (Y2) }\end{array}$ & $\begin{array}{c}\text { Service Quality } \\
\text { (X1) }\end{array}$ & $\begin{array}{c}\text { Social Envir. } \\
\text { (X2) }\end{array}$ \\
\hline Athlete Performance (Y3) & $\mathbf{0 . 7 4 6}$ & & & & & \\
\hline Financial (X3) & 0.384 & $\mathbf{0 . 7 1 9}$ & & & & \\
\hline Motivation (Y1) & 0.416 & 0.165 & $\mathbf{0 . 7 6 4}$ & & & \\
\hline Satisfaction (Y2) & 0.512 & 0.711 & 0.297 & $\mathbf{0 . 7 3 5}$ & & \\
\hline Service Quality (X1) & 0.611 & 0.671 & 0.318 & 0.774 & $\mathbf{0 . 7 1 8}$ & \\
\hline Social Environment (X2) & 0.431 & 0.392 & 0.438 & 0.51 & 0.543 & $\mathbf{0 . 7 2 1}$ \\
\hline
\end{tabular}

Discriminant validity among variables was also among the staples of this study. In the book of Prof Dipak C. Jain 2019 entitled "Mastering Partial Least Squares Structural Equation Modeling (PLS-SEM) with Smart-PLS in 38hours, there are two paths to check discriminant validity: the Fornell-Larcker Criterion and HTMT. The classical approach is proposed by Fornell and Larcker (1981) who postulated that the square root of AVE in each latent variable can be used to set up discriminant validity if this value is larger than other correlation values among the latent variables. To do this, a table is created in which the square root of AVE is manually calculated and written in bold on the diagonal of the table. For example, AVE of the latent variable athlete performance is found to be 0.557 , hence its square roots on the same variable (athlete performance) becomes 0.746 . This number is larger than the correlation values in the column of athlete performance (0.384, 0.416, 0.512, 0.611, and 0.431 respectively). A similar observation is also made for the latent variable financial support, motivation, satisfaction, service quality, and social environment (Tables $1 \& 3$ ). The present results indicate that discriminant validity is well established among research variables.

There is a Linear Regression between Dependent and Independent Variables

In a broad sense, regression analysis is concerned with predicting the mean value of a dependent variable $Y$ from known values of one or more independent variables $X i$. The p variable model with a dependent variable $Y$, and $\mathrm{p}$ independent variables $X 1, X 2, X 3, \ldots X p$ can be written as:

$$
\mathrm{Yi}=\beta \mathrm{o}+\beta 1 \mathrm{X} 1+\beta 2 \mathrm{X} 2+\ldots .+\beta \mathrm{p} \mathrm{Xp}+\varepsilon \mathrm{i}
$$

In equation (1), $\beta o$ denotes the intercept, $\beta 1, \ldots, \beta p$ the partial regression (slope) coefficients, and $\varepsilon i$ the residual term. Basically, $\beta o$ and $\beta i$ 's are estimated to be as close to the corresponding population parameters as possible using the method of ordinary least squares (OLS) [36]. It is also a common statistical data analysis technique that uses a single independent variable to predict the value of the dependent variables. In other terms, a linear regression line has an equation of the for $\mathrm{Y}=\mathrm{a}+\mathrm{bX}$, where $\mathrm{X}$ is the explanatory variable and $\mathrm{Y}$ the dependent variable. In this research, the explanatory variables are in the number of three, namely service quality, social environment, and financial support, and satisfaction, motivation, and athlete performance as dependent variables. With the software SPSS. 23, this research hypothesis has been tested and verified:

H0: There are no relationships among the following variables: service quality, financial support, social environment, motivation, satisfaction, and athlete performance.

Ha: There are significant relationships between independent and variables cited in the previous hypothesis. 
Table 4. Linear Regression Hypothesis Test

\begin{tabular}{|c|c|c|c|c|c|}
\hline & $\begin{array}{c}\text { Original } \\
\text { Sample (O) }\end{array}$ & $\begin{array}{c}\text { Sample } \\
\text { Mean (M) }\end{array}$ & $\begin{array}{c}\text { Standard Deviation } \\
\text { (STDEV) }\end{array}$ & $\begin{array}{c}\text { T Statistics } \\
(|\mathrm{O} / \mathrm{STDEV}|)\end{array}$ & P-Values \\
\hline $\begin{array}{c}\text { Financial (X3) -> Athlete } \\
\text { Performance (Y3) }\end{array}$ & -0.061 & -0.056 & 0.121 & 0.502 & 0.616 \\
\hline Financial (X3) -> Motivation (Y1) & -0.107 & -0.114 & 0.097 & 1.105 & 0.27 \\
\hline Financial (X3) -> Satisfaction (Y2) & 0.349 & 0.335 & 0.077 & 4.557 & 0 \\
\hline $\begin{array}{c}\text { Motivation (Y1) -> Athlete } \\
\text { Performance (Y3) }\end{array}$ & 0.224 & 0.219 & 0.075 & 2.973 & 0.003 \\
\hline $\begin{array}{c}\text { Motivation (Y1) -> Satisfaction } \\
\text { (Y2) }\end{array}$ & 0.046 & 0.04 & 0.044 & 1.058 & 0.291 \\
\hline $\begin{array}{c}\text { Satisfaction (Y2) -> Athlete } \\
\text { Performance (Y3) }\end{array}$ & 0.088 & 0.094 & 0.151 & 0.578 & 0.563 \\
\hline $\begin{array}{c}\text { Service Quality (X1) -> Athlete } \\
\text { Performance (Y3) }\end{array}$ & 0.486 & 0.472 & 0.153 & 3.179 & 0.002 \\
\hline $\begin{array}{c}\text { Service Quality (X1) -> Financial } \\
\text { (X3) }\end{array}$ & 0.649 & 0.662 & 0.058 & 11.133 & 0 \\
\hline $\begin{array}{c}\text { Service Quality (X1) -> } \\
\text { Motivation (Y1) }\end{array}$ & 0.184 & 0.186 & 0.098 & 1.875 & 0.061 \\
\hline $\begin{array}{l}\text { Service Quality (X1) -> } \\
\text { Satisfaction (Y2) }\end{array}$ & 0.472 & 0.478 & 0.07 & 6.707 & 0 \\
\hline $\begin{array}{c}\text { Service Quality (X1) -> Social } \\
\text { Environment (X2) }\end{array}$ & 0.543 & 0.549 & 0.085 & 6.399 & 0 \\
\hline $\begin{array}{l}\text { Social Environment (X2) -> } \\
\text { Athlete Performance (Y3) }\end{array}$ & 0.049 & 0.06 & 0.116 & 0.42 & 0.675 \\
\hline $\begin{array}{c}\text { Social Environment (X2) -> } \\
\text { Financial (X3) } \\
\end{array}$ & 0.039 & 0.041 & 0.095 & 0.416 & 0.677 \\
\hline $\begin{array}{c}\text { Social Environment (X2) -> } \\
\text { Motivation (Y1) }\end{array}$ & 0.38 & 0.395 & 0.076 & 5.026 & 0 \\
\hline $\begin{array}{c}\text { Social Environment (X2) -> } \\
\text { Satisfaction (Y2) } \\
\end{array}$ & 0.097 & 0.106 & 0.067 & 1.456 & 0.146 \\
\hline
\end{tabular}

We notice that the data highlighted in red colors indicate where strong relationships were found and vice versa. Thus, to simplify this data above, we just look at the column where mentioned P-value to see whether the relationship calculated among independent and dependent variables are statistically significant or not. The theory said, if the $\mathrm{p}$-calculated is lower than the $p$-value, which means the relationship found is statistically significant. Thus, in this study, data showed that a substantial portion of the results was not significant with their values ranging from 0.616 as the highest value to 0.061 as the lowest result. This means that there is a weak relationship between the combination indicators variables and between variables themselves. For data where the results load with a strong relationship based on p-value $<0.05$, it shows that the highest significant value was 0.003 and the lowest was 0.000 . We deduced that coaches, athletes, athletes' parent, policymakers in KONI in Yogyakarta need to enhance the relations between service quality, social environment, satisfaction, motivation, financial means, and in the wake of improving athlete performance. We recall here that the main purpose of this data above to search the correlation which would be between indicators-constructs and the variables in between. Then, the regression search enabled us to see if the independent variables predict the values of the dependent variables.

\section{Discussion}

We have analyzed the link between service quality, social environment, and financial supports in relation to the effects of motivation, satisfaction, and athlete performance among KONI athletes in Yogyakarta. Apart from that, we impart that the gist of this study was to find out the relationship between dependent and independent variables among athletes. Since this study is conducted on athletes with various and multiple variables, we argue that it will contribute to the literature review in terms of being different from the researchers conducted for a single or two variables. For [22] the proposed research model examines the perception or liaison of service quality on athletes' satisfaction through their attitude and recommendations. In their results of the analyses based on averages, it was observed that service quality has a significant effect and the satisfaction level of athletes and their perceptions toward service quality was high. This previous evidence was also found in this study even though its value of association was 0.678 .

The results of the sample used, structural equation modeling (SEM) and linear regression, and statistics calculations prove that there is a significant relationship between some dependent variables and independent variables. Nevertheless, correlation in some cases of some indicators with independent and dependent variables, or 
between variables themselves was not all significant. Some of which are showcased in table 4 above with a p-value $>$ 0.05 . When seeking the relation between financial supports (that consists of extra meal and diet, pocket money, and transportation fee provided to athletes) on athlete satisfaction and performance, results showed that the existence of relationship among them even though it is not firm. Our study findings were corroborated with the one conducted by [5] which studied the effect of parental support and sports accomplishment on athletes. Supported by one-way ANOVA while analyzing data, their findings were summarized in this following statement: “...the family environment may be the most accessible as well as the most important of the socio-environmental dimensions of young athletes.”

As a brief reminder, this research employed three main hypotheses that led to all analysis and interpretation. Thus, all so-called hypotheses were verified by the results of this study. The first hypothesis concerned the significant correlation of research indicators and variables. On the first variable, such is service quality with four indicators (empathy, responsiveness, assurance, and reliability) that the high service quality implies the better value of indicator respectively. After testing with Smart-PLS software, we have confirmed this evidence when all loading values were above 0.5 , where the highest value stands at 0.802 and the lowest equal to 0.567 . The social environment was another variable used in this study that connected to three indicators, such as family support, school, and people. Addressed data showed that tough correlation was found based on the loading value ranged from 0.529 as the lowest and 0.823 as the highest. While testing financial support together with extra-meal/nutritional food, transportation fee, and pocket money as attributed indicators, results also revealed such liaison with data ranged from 0.622 to 0,828 . The same signification was also found between the rest of the variables and indicators as mentioned in the previous passages. The most interesting fact the research obtained from finding yielded was that parents' involvement was correlated with their athletes' level of sports performances.

The second hypothesis concerned whether there is a positive correlation between dependent and independent variables. It was expected that service quality given to athletes would score higher in scare/loading values if correlated with satisfaction level, motivation, athlete performance, financial support, or social environment. However, the hypothesis was only partly confirmed when a big portion of loading value felt under 0.05, except for the relationship between service quality and athlete satisfaction which equals 0.678 .

The third hypothesis concerned the linear regression between dependent and independents variables. As aforementioned in the previous sections, linear regression statistics calculations prove that there is a significant value between some dependent variables and independent variables, along with correlation significance of some indicators with the dependent and independent variables. In detail, significant-linear regression values inferior at p-value 0.05 was 0.00 between financial support on athlete satisfaction, 0.003 for motivation and athlete performance, 0.002 between service quality and athlete performance, 0.000 for service quality and financial support, 0.062 at service quality and motivation, 0.00 on service quality and social environment and between social environment and motivation. However, linear regression was not found significant with p-value $>0.05$ on the following variables; it was not significant like: financial support to athlete performance $(0.616>0.05)$, financial support and motivation $(0.27>0.05)$, motivation and satisfaction $(0.291>0.05)$, satisfaction and athlete performance $(0.563>0.05)$, service quality and motivation $(0.062>0.05)$, social environment and athlete performance $(0.675>0.05)$ social environment and financial support ( $0.677>0.05)$, and eventually between social environment and satisfaction $(0.146>0.05)$. The finding above showed points which need to be improved. In contrast, some works of literature found a strong linear regression among these variables delt in this study even though researchers did not present the rational reasons on why data have such features. For example, [37] with the topic ''Examining the Relationship Between Social Support Satisfaction and Perceived Stress and Depression in Athletic Training Students", with the main objective to determine the most salient and ascertain whether social support satisfaction can predict stress and depression among athletic training students, the perceived stress found was with $(\mathrm{P}=.010)$ and depression $(\mathrm{P}=.001)$. In the same vein, the satisfaction of support from family was also found significant with $(\mathrm{P}=.043)$ and other athletic trainers $(\mathrm{P}=.011)$ were significant predictors of perceived stress. On the effect of social environment on athlete performance [38], [39], relationships between coaching behaviors and attribution dimensions such as athlete attributional styles were found.

\section{Conclusions}

Understanding the social environment of groups in term of service quality is an art of athleticism to be featured by undeniable important. The results of our research have shown that the quality of service offered in public sports facilities has a huge impact on different constructs employed in this study, namely social environment, and financial support from different facets, athlete satisfaction, motivation, and performance. As a reminder, this study had responded to a different calls from further research who argued for example the existence of a strong relation between soccer clubs' financial results and athletes performance [40], [41]. Our finding have confirmed previous authors' arguments that service quality, financial state or spending more money on athletes could be more successful in the competitions or championships, [42], [43]. 
Based on the discussions that have been put forward, the conclusion can be drawn. Correlation traits have been found within most research variables even though in some cases it was not tough. Therefore, precautions for the high quality of service, social environment, and financial support as sports facilities belonging to KONI-Yogyakarta can be improved by taking into consideration the quality perception and the expectation of the athletes. This approach could not be only ensured the promotion policy but also has increased the well-being and achievement of athletes. The quality of service would create an effective promising outcome for athletes being trained. At the same time, it is important to design and implement a certain program that may nurture to improve coachers' skills and knowledge by giving them service training for the same purpose (improve athlete performance). Previous studies have indicated that student athletes' perceived service quality could differ based on demographic variables like gender, status, age, etc. and the moderation effects might exist in the relationship among service quality, event value and satisfaction [25], [15], [44]. However, the latter evidence was seen as one of the limitations in this present study. Another shortcoming suggested was that longitudinal studies may be conducted in the future to scrutinize the consistency of the model employed. Also, it was suggested that future researchers could carry out in-dept inquiries of athletes for further understanding as to how and why these service qualities play such paramount a role.

\section{Acknowledgements}

We warmly thank the participants in our research who have given written consent, but also, we deeply felt gratitude to address to the KONI staff and athletes who willingly partook and made this research possible by supplying useful information.

\section{Conflict of Interest}

No significant conflict was reported by authors from the outset up to the end of the final product.

\section{REFERENCE}

[1] M. Sarkar and D. Fletcher, "Psychological resilience in sport performers: a review of stressors and protective factors," $J$. Sports Sci., vol. 32, no. 15, pp. 1419-1434, 2014, doi: 10.1080/02640414.2014.901551.

[2] A. C. Moreira and P. M. Silva, "The trust-commitment challenge in service quality-loyalty relationships,” Int. J. Health Care Qual. Assur., vol. 28, no. 3, pp. 253-266, 2015, doi: 10.1108/IJHCQA-02-2014-0017.
[3] B. Mohamed and N. A. Azizan, "Perceived service quality's effect on patient satisfaction and behavioural compliance," Int. J. Health Care Qual. Assur., vol. 28, no. 3, pp. 300-314, 2015, doi: 10.1108/IJHCQA-06-2014-0074.

[4] Q. Chen and T. Liu, "The effectiveness of community sports provision on social inclusion and public health in rural China," Int. J. Environ. Res. Public Health, vol. 17, no. 2, 2020, doi: 10.3390/ijerph17020597.

[5] M. Siekańska, “Athletes’ perception of parental support and its influence on sports accomplishments - A retrospective study,” Hum. Mov., vol. 13, no. 4, pp. 380-387, 2012, doi: 10.2478/v10038-012-0046-x.

[6] K. Preckel, P. Kanske, and T. Singer, "On the interaction of social affect and cognition: empathy, compassion and theory of mind,” Curr. Opin. Behav. Sci., vol. 19, pp. 1-6, 2018, doi: 10.1016/j.cobeha.2017.07.010.

[7] S. Li, Y. Wang, J. Xue, N. Zhao, and T. Zhu, "The impact of covid-19 epidemic declaration on psychological consequences: A study on active weibo users. Int J Environ Res Public Health [revista en Internet] 2020 [acceso 13 de abril de 202021]; 30(3): 201-205,” Int. J. Environ. Res. Public Health, vol. 17, no. 6, 2020, [Online]. Available: https://www.ncbi.nlm.nih.gov/pmc/articles/PMC7143846/p df/ijerph-17-02032.pdf.

[8] S. Kane et al., "Limits and opportunities to community health worker empowerment: A multi-country comparative study," Soc. Sci. Med., vol. 164, no. July, pp. 27-34, 2016, doi: 10.1016/j.socscimed.2016.07.019.

[9] Undp, "Incentive Systems: Incentives, Motivation, and Development Performance,” Conf. Pap. \#8, no. November, pp. 1-25, 2006.

[10] V. D. Cardoso, M. de Castro Haiachi, A. R. R. Filho, and A. C. A. Gaya, "Financial support for paralympic athletes in Brazil,” J. Phys. Educ., vol. 29, no. 1, pp. 1-10, 2018, doi: 10.4025/jphyseduc.v29i1.2963.

[11] J. Schoonenboom and R. B. Johnson, "Wie man ein Mixed Methods-Forschungs-Design konstruiert," Kolner Z. Soz. Sozpsychol., vol. 69, pp. 107-131, 2017, doi: 10.1007/s11577-017-0454-1.

[12] R. Thwaites, "Research design and methodology," Chang. Names Gendering Identity, pp. 32-42, 2020, doi: 10.4324/9781315571256-9.

[13] C. Neville, "Effective Learning Service: Introduction to Research and Research Methods," Bradford Univ. Sch. Manag., pp. 1-44, 2007.

[14] E. T. C. Lam, J. J. Zhang, and B. E. Jensen, "Service Quality Assessment Scale (SQAS): An instrument for evaluating service quality of health-fitness clubs,” Meas. Phys. Educ. Exerc. Sci., vol. 9, no. 2, pp. 79-111, 2005, doi: 10.1207/s15327841mpee0902_2.

[15] A. Saoud, A. Elamri, K. Kimakh, M. Ziani, M. Matar, and M. Chergui, "Technological characterization and correlation between mechanical and physical properties of the wood of Thuja (Tectracanalis Articulata) of the khemissat region in Morocco,” ARPN J. Eng. Appl. Sci., vol. 13, no. 2, pp. 632637, 2018.

[16] L. Ferri, R. Macchioni, M. Maffei, and A. Zampella, 
"Financial Versus Sports Performance: The Missing Link," Int. J. Bus. Manag., vol. 12, no. 3, p. 36, 2017, doi: 10.5539/ijbm.v12n3p36.

[17] A. A. Donnelly et al., "Environmental influences on elite sport athletes well being: From gold, silver, and bronze to blue green and gold," Front. Psychol., vol. 7, no. AUG, pp. 1-6, 2016, doi: 10.3389/fpsyg.2016.01167.

[18] J. Elia, N. Khaddage-Soboh, L. Chahine, M. Hamieh, and Y. Kassem, "Motivations and barriers that impact Lebanese Athletes' achievements at the Olympics,” Int. J. Organ. Anal., vol. 28, no. 2, pp. 333-364, 2020, doi: 10.1108/IJOA-05-2019-1777.

[19] Y. Murugeesan, N. Ain, and M. Hasan, "Review of Factors Influencing the Coach- - - Athlete Relationship in Malaysian Team Sport Factors Influencing the Coach- - Athlete Relationship: Western and Asian Perspectives," Malaysian J. Soc. Sci. Humanit., vol. 1, no. 3, pp. 83-98, 2016.

[20] M. Sarstedt, M. Schwaiger, and C. M. Ringle, "Do We Fully Understand the Critical Success Factors of Customer Satisfaction with Industrial Goods? - Extending Festge and Schwaiger's Model to Account for Unobserved Heterogeneity,” J. Bus. Mark. Manag., vol. 3, no. 3, pp. 185206, 2009, doi: 10.1007/s12087-009-0023-7.

[21] N. Gillet, S. Berjot, R. J. Vallerand, S. Amoura, and E. Rosnet, "Examining the motivation-performance relationship in competitive sport: A cluster-analytic approach,” Int. J. Sport Psychol., vol. 43, no. 2, pp. 79-102, 2012.

[22] İ. Günel and M. Duyan, “The Effect of Service Quality on Athlete Satisfaction: An Empirical Results From Sports Facilities,” Eur. J. Manag. Mark. Stud., pp. 51-65, 2020, doi: 10.46827/ejmms.v5i3.830.

[23] L. Martin, M. Bruner, M. Eys, and K. Spink, "The social environment in sport: Selected topics International Review of Sport and Exercise Psychology The social environment in sport: selected topics,” no. September 2015, 2014, doi: 10.1080/1750984X.2014.885553.

[24] J. Moradi, A. Bahrami, and A. Dana, "Motivation for participation in sports based on athletes in team and individual sports,” Phys. Cult. Sport. Stud. Res., vol. 85, no. 1, pp. 14-21, 2020, doi: 10.2478/pcssr-2020-0002.

[25]D. Lee, "Relationships among Service Quality , Value , and Student Athlete Satisfaction at Taiwan' s National Tug of War Competition,” vol. 12, no. 3, pp. 275-288, 2016, doi: 10.7903/cmr.15852.

[26] J. Esteve-Lanao, C. Foster, S. Seiler, and A. Lucia, "Impact of training intensity distribution on performance in endurance athletes,” J. Strength Cond. Res., vol. 21, no. 3, pp. 943-949, 2007, doi: 10.1519/R-19725.1.

[27] S. M. Rasoolimanesh, C. M. Ringle, M. Jaafar, and T. Ramayah, "Urban vs. rural destinations: Residents' perceptions, community participation and support for tourism development,” Tour. Manag., vol. 60, no. September 2018, pp. 147-158, 2017, doi: 10.1016/j.tourman.2016.11.0 19.

[28] W. Reinartz, M. Haenlein, and J. Henseler, “An empirical comparison of the efficacy of covariance-based and variance-based SEM,” Int. J. Res. Mark., vol. 26, no. 4, pp. 332-344, 2009, doi: 10.1016/j.ijresmar.2009.08.001.

[29] W. W. Chin, Handbook of Partial Least Squares. 2010.

[30] J. F. Hair, M. Sarstedt, C. M. Ringle, and J. A. Mena, “An assessment of the use of partial least squares structural equation modeling in marketing research,” J. Acad. Mark. Sci., vol. 40, no. 3, pp. 414-433, 2012, doi: 10.1007/s11747-011-0261-6.

[31] E. H. Hernández, P. C. Blanco, A. G. Rodríguez, and J. M. Martín, "Design and validation of an observational instrument to assess the technical execution in top-rope climbing,” J. Hum. Sport Exerc., vol. 9, no. 1, pp. 111-123, 2014, doi: 10.4100/jhse.2014.91.12.

[32] Ilham and Tomoliyus, "Construction of validity and reliability of an observational instrument to assess the technical execution in lead climbing," Int. J. Hum. Mov. Sport. Sci., vol. 9, no. 3, pp. 403-411, 2021, doi: 10.13189/saj.2021.090303.

[33] J. F. Hair, C. M. Ringle, and M. Sarstedt, "PLS-SEM: Indeed a silver bullet,” J. Mark. Theory Pract., vol. 19, no. 2, pp. 139-152, 2011, doi: 10.2753/MTP1069-6679190202.

[34] I. Corresponding, "Partial Least Squares Structural Squation Modeling ( PLS-SEM ) Analysis for Social and Management Research: A Literature Review Agus Purwanto Journal of Industrial Engineering \& Management Research,” vol. 2, no. 4, pp. 114-123, 2012.

[35] J. Ndayisenga and Tomoliyus, “The perception of international students on the facility and sport tourism event management,” Sport Mont, vol. 17, no. 2, pp. 53-58, 2019, doi: 10.26773/smj.190609.

[36]D. P. Mishra and J. Min, “Analyzing the Relationship between Dependent and Independent Variables in Marketing: A Comparison of Multiple Regression with Path Analysis,” SSRN Electron. J., no. December, 2013, doi: 10.2139/ssrn.2259524.

[37] B. Crutcher, R. N. Moran, and T. Covassin, "Examining the Relationship Between Social Support Satisfaction and Perceived Stress and Depression in Athletic Training Students,” Athl. Train. Educ. J., vol. 13, no. 2, pp. 168-174, 2018, doi: 10.4085/1302168.

[38] U. Britton, "The relationship between coaching environment and athlete attributional style,” Dissertation, no. January, p. 74, 2015, [Online]. Available: https://encompass.eku.edu/et d\%0Ahttps://proxy.library.mcgill.ca/login?url=https://searc h.proquest.com/docview/1686537079?accountid=12339.

[39] I. Ilham and D. Dimyati, "The Effect of Visualization, Relaxation, and Self-efficacy on the Performance of Men Speed World Record Athletes Category,” Int. J. Hum. Mov. Sport. Sci., vol. 9, no. 1, pp. 48-55, 2021, doi: 10.13189/saj.2021.090107.

[40] D. E. Panagiotis, "Profitability of the Greek football clubs: Implications for financial decisions making," Oper. Manag. A Mod. Approach, no. July, pp. 169-182, 2011, doi: 10.1201/b12879-10.

[41] U. Lago, R. Simmons, and S. Szymanski, "The Financial Crisis in European Football: An Introduction,” J. Sports Econom., vol. 7, no. 1, pp. 3-12, 2006, doi: $10.1177 / 1527002505282871$. 
[42] B. Frick and R. Simmons, "The impact of managerial quality on organizational performance: Evidence from German soccer," Manag. Decis. Econ., vol. 29, no. 7, pp. 593-600, 2008, doi: 10.1002/mde.1431.

[43] S. Hall, S. Szymanski, and A. S. Zimbalist, "Testing Causality Between Team Performance and Payroll: The Cases of Major League Baseball and English Soccer,” $J$.
Sports Econom., vol. 3, no. 2, pp. 149-168, 2002, doi: $10.1177 / 152700250200300204$.

[44] J. Ndayisenga and Tomoliyus, "Effect of service quality and rates on satisfaction and loyalty of customer behavior at fitness,” Int. J. Hum. Mov. Sport. Sci., vol. 7, no. 2, pp. 25-32, 2019, doi: 10.13189/saj.2019.070202. 